\title{
WHY DO (W)EEE HOARD? THE EFFECT OF CONSUMER BEHAVIOUR ON THE RELEASE OF HOME ENTERTAINMENT PRODUCTS INTO THE CIRCULAR ECONOMY
}

\author{
Ariadne Wilkinson ${ }^{1}$ and Ian Williams ${ }^{2, *}$ \\ ${ }^{1}$ CBRE Ltd - EMEA Energy \& Sustainability, United Kingdom of Great Britain and Northern Ireland Building, Garthdee Road, Aberdeen \\ AB10 7GJ, United Kingdom \\ ${ }^{2}$ University of Southampton, Faculty of Engineering and the Environment, University Rd, Highfield, Southampton SO17 1BJ, United \\ Kingdom
}

Article Info:

Received:

11 January 2020

Revised:

30 April 2020

Accepted:

5 May 2020

Available online

7 September 2020

Keywords:

Waste management

Waste electrical and electronic

Equipment (WEEE)

End-of-life (EoL)

Behaviour

Home entertainment products

Distinct Urban Mines (DUM)

\begin{abstract}
Waste electrical and electronic equipment (WEEE) continues to grow due to rising consumer demand for technologically advanced and affordable electronic products. Home entertainment (HE) products are particularly rich in metals and plastics and thus have enormous potential as a source of materials from the anthroposphere, especially from within Distinct Urban Mines (DUMs). Consumers' end-of-life (EoL) management decisions (i.e. stockpiling, hoarding, reusing, discarding of WEEE) strongly influence the exploitation potential of a DUM. This study aimed to assess the effect of consumer behaviour on the release of HE (W)EEE into the circular economy. A survey was undertaken in Southampton (Hampshire, UK) to assess perceptions and behaviours relating to the EoL management of HE (W)EEE. The study provides previously unavailable data and critical evaluation on the ownership, use and hoarding levels of HE EEE in a typical city DUM, and the reasons behind their hoarding. Results indicated that ownership levels were very high, with an average of 12 home entertainment items owned per household. This makes urban areas extremely plausible as DUMs; we estimate that there are over 1 million HE devices owned and $\sim 440,000$ HE devices hoarded in Southampton and $>150$ million HE EEE owned and 61 million HE devices hoarded in UK households. Hoarding is common, especially for smaller or older equipment, due to their perceived residual value. HE product lifecycles averaged 4-5 years. The most common EoL routes were donating to relatives, friends or charities; hoarding; recycling via Household Waste Recycling Centres; or discarding items in general refuse. To encourage the recovery of EoL HE equipment in a DUM: i) convenient and accessible WEEE collection points should be established for regular (periodic) harvesting and ii) promoted via awareness campaigns and incentives.
\end{abstract}

\section{INTRODUCTION}

\subsection{Hoarding of WEEE}

The rapid technological advancements of the past decades, a growing market of affordable Electrical and Electronic Equipment (EEE) and shorter product lifespans have resulted in huge quantities of electronic waste (e-waste) being produced globally (Imran et al., 2017; Ongondo \& Williams, 2012). At present, e-waste (also known as waste electrical and electronic equipment, WEEE) is one of the fastest-growing waste streams in the world, with 40-50 million tonnes being produced globally every year at an annual growth rate of $4-5 \%$ (Golev et al., 2016). WEEE poses an unavoidable waste management challenge for both developed and developing countries. Its huge global quantities, impacts on natural resources, as well as the potential human health, environmental and ethical concerns associated with its end-of-life (EoL) management if treated through rudimentary means (i.e. 'backyard recycling'), make the sustainable management of WEEE a global issue (Baldé et al., 2015; Hursthouse et al., 2017; Lodhia et al., 2017). EEE come to their EoL when they cease to function or be of any value to their owners, at which point they become WEEE (Ongondo \& Williams, 2011a).

Market forces (e.g. technological advances or fashion), consumer behaviour and product features such as their material composition, condition, or reusability stimulate the generation of WEEE in throwaway societies (van Barneveld et al., 2016; Benton, 2015). Promoting a slower rate of consumption and the reuse of EEE purchases can 
help alleviate current challenges associated with WEEE production. Indeed, reuse of products has come into fashion again (Williams \& Shaw, 2017) with the emergence of the so-called 'sharing economy', in which underutilized possessions are shared (or re-sold) through peer-to-peer exchanges, enabling more efficient use of products alongside economic and social benefits (Fletcher \& Dunk, 2018; Cherry and Pidgeon, 2018; Martin, 2016). In the United Kingdom, the charity retail sector is becoming an increasingly significant player in terms of demonstrating the benefits of reuse and how it can be practically realized (Osterley \& Williams, 2019). Under a sustainable closed-loop circular economy, resources within WEEE such as plastics, glass and metals are recovered, ultimately reducing the need for further extraction of raw materials (Schluep et al., 2009; Ongondo \& Williams, 2012). Modern high-tech EEE such as home entertainment equipment are especially rich in metals and critical raw materials (e.g. platinum group metals and rare earth elements) and make up a large proportion of anthropogenic stocks (Massari \& Ruberti, 2013; Golev et al., 2016; Williams, 2016). These secondary resources may be exploited via urban mining, helping the transition towards a circular economy (Izzat et al., 2014; Ongondo et al., 2015; Simon \& Holm, 2018). Ideal locations for urban mining - known as Distinct Urban Mines (DUMs) - include urban hubs such as cities and universities, which have clear geographical boundaries, localised populations and quantifiable anthropogenic (W)EEE stocks as well as material flows (Pierron et al., 2017). Material stocks can be associated with in-use and hibernating (hoarded or stockpiled) (W)EEE in society, while material flows involve the reuse, recycling and discarding of EoL electronics (Pierron et al., 2017). To ensure the recovery of material stocks within a DUM, it is important to recognise potential hindrances to the circular flow of products and resources.

Poor recovery efforts for (W)EEE currently dictate that the majority of this waste stream is improperly disposed of, stockpiled or hoarded in society, or illegally exported to developing countries (van Barneveld et al., 2016; Imran et al., 2017; Pierron et al., 2017; Osibanjo \& Nnorom, 2007). These factors generate serious environmental concerns, as they prevent the exploitation of a large proportion of material stocks, resulting in the extraction of additional natural resources to meet product demand (Ongondo \& Williams, 2011a). In the EU alone, it is reported that from the 12 million tonnes of WEEE disposed of annually, only $30 \%$ is properly collected and recycled (Williams, 2016); with most small WEEE such as Universal Serial Bus (USB) sticks, mobile phones, electric toothbrushes, or lamps ending up in the general waste (Baldé et al., 2015). Consumer behaviours associated with their intent to sell, reuse, recycle, discard, or hoard (W)EEE determines the extent of an urban mine's exploitation.

Hoarding occurs when consumers indefinitely store obsolete EEE that are no longer used or wanted. This is a major barrier to accessing an urban mine and releasing exploitable materials into the CE. The average household in the United States of America (USA) hoards 4.1 small $(>4.5 \mathrm{~kg})$ and 2.4 large electronic items in their attic or basement, mainly due to ample storage space, preventing their recycling or reuse (Saphores et al., 2009). In Europe and the United Kingdom (UK), hoarding is common for (W)EEE with a perceived residual value (e.g. monetary, functional, sentimental), such as mobile phones (Ongondo \& Williams, 2011a). Access to an urban mine primarily depends on the availability of resources for a given type of (W)EEE. Hoarded items that are currently unavailable (hibernating stocks) greatly reduce the exploitation potential of anthropogenic resources since they are stored in homes indefinitely. Ideally, (W)EEE should be stockpiled/hoarded with the intent of releasing it into the CE instead; which will ensure future access to a DUM's unexploited resource stocks. To gain insight on a DUM and facilitate a closed loop system for resource and material flows, it is essential to quantify the ownership and use levels for (W)EEE as well as the EoL practices and dispositions of consumers.

The primary aim of this study was to assess the effect of EoL consumer behaviours on the release of home entertainment (HE) (W)EEE into the circular economy. The objectives were to: i) determine the technological advances in HE EEE through time by producing evolutionary timelines for audio, visual and interactive electronic devices; ii) identify and evaluate the types and quantities of HE (W)EEE that consumers own, use and hoard; iii) establish and analyse the reasons behind consumer hoarding; and iv) evaluate and critically discuss consumer purchasing, hoarding, gifting, selling and disposing behaviours for HE (W)EEE, to establish how they might be addressed to achieve a CE.

We critically discuss findings in the context of the technological and fashion-related evolution of HE electronic products, whilst considering urban areas as a potential DUM under the framework discussed by Pierron et al. (2017), using the city of Southampton as an exemplar.

\subsection{Evolution of home entertainment technologies}

Since their invention, HE systems in the form of audio devices (speakers and radios), televisions, video players and games consoles have revolutionised the market economy globally. Through the decades, the growing demand for the production of electronic goods within developed economies has been gradually reinforcing the principles of a "throwaway society", which are associated with rapid product replacement and high market competition (Williams, 2016). An analysis of the evolution of HE EEE from 1861 until the present day is depicted in Appendix 1, which documents and illustrates how audio speakers, televisions and video players, and game consoles have evolved from inception to the present day. Insight on the technological advancements and fashion-related evolution of such products contributes to the understanding of current HE EEE, the relationship between manufacturers and consumers and EoL behaviours.

\section{METHODS}

\subsection{Postal survey}

Primary data was collected from residents of the city of Southampton (Hampshire, UK) via a postal survey, during the course of 3 months in January-March 2018. The design of the survey built upon the approach used in pre- 
vious studies (e.g. Bergland and Matti, 2006; Timlett and Williams, 2009, Ongondo \& Williams, 2011b). The self-administered questionnaire (Appendix 2) incorporated questions to: (a) assess community perceptions, behaviours, and dispositions related to the EoL management of $\mathrm{HE}(\mathrm{W})$ EEE; (b) establish the types of HE (W)EEE consumers own, use, and stockpile/hoard in their homes; and (c) determine the reasons behind these tendencies. The questionnaire sought information on respondents' demographic characteristics, household size and storage space. Respondents' dispositions and behavioural tendencies were determined to distinguish between respondents' intent to act and past actions. The survey was permitted via the University of Southampton's standard procedures for risk assessment (code FEERA 15034) and ethical approval (code ERGO II 40143).

The questionnaire was piloted among twelve participants from the target population prior to data collection, to ensure ease-of-understanding, ease-of-use, and content validity. Questions were modified as a consequence of feedback received from the pilot survey. A participant information sheet was attached to the final questionnaire to provide simple instructions and to answer potential participant queries.

Seven hundred and twenty questionnaires were hand-delivered across Southampton households within four pre-selected wards. These locations were selected to ensure a representative sample incorporating all levels of household affluence, as determined by the UK's Index of Multiple Deprivation (IMD) of 2015 (OpenDataCommunities.org, 2015). The four wards represented levels of high (Redbridge ward: 10\% most deprived), average-high (Swaythling ward: $30-40 \%$ most deprived), average-low (Bargate ward: $50 \%$ least deprived) and low (Upper Shirley ward: $10-$ $20 \%$ least deprived) deprivation within the city.

One hundred and eighty questionnaires were posted in each ward across randomly selected households and collected in person a week after delivery. To encourage a higher response rate, three collection attempts were made per household. Questionnaires were coded by ward, and household numbers were documented separately to enable future collection attempts.

\subsection{Statistical analysis}

The results were analysed using SPSS 20 (IBM Ltd). Non-parametric tests were applied to examine hoarding habits and reasons behind such behaviour, and compare between hoarding reasons, home entertainment (W)EEE gifting, selling and disposal routes, as well as according to respondent demographics.

A chi-square test was carried out for association between age, gender, educational level, deprivation zone, household size, household storage space and hoarding habits (whether respondents hoarded or not). Z-scores from the chi-square cross-tabulation table were compared to examine the relationship of the significant associations.

Kruskal-Wallis tests were performed to assess for a significant difference between respondent demographic variables (age, gender, educational level, deprivation zone, household size, household storage space) and hoarding reasons (functional, social, sentimental, monetary and lack-of-awareness reasons). A series of post-hoc Mann-Whitney $U$ tests were performed on the significant results, to examine where the significance lies within each demographic variable and hoarding reason.

A Friedman's analysis of variance test was performed to examine whether hoarding reasons differ significantly from one another. Wilcoxon signed-rank tests were applied to rank hoarding reasons in order of their influence on respondents' hoarding dispositions. A Friedman's analysis of variance test was also carried out to examine the significance between home entertainment (W)EEE gifting, selling and disposal routes. Wilcoxon signed-rank tests were subsequently applied to rank the gifting, selling and disposal routes in order of likelihood of opting for each route, as indicated by survey respondents.

\section{RESULTS}

A total of 139 useable questionnaires were collected (19\% response rate). The results of the survey are presented in the following sections. Respondent behaviours (previous past actions; sections 3.1 and 3.2) and dispositions (intent to act; section 3.3) have been analysed separately, to differentiate between past consumer hoarding practices and behavioural tendencies. The results were broadly representative for each deprivation zone and gender, although more respondents from the younger age groups completed the survey than from the older $(61 \%$ of respondents were 18-24 and $25-44$ years, whereas only $12 \%$ of respondents were $65+$ years).

\subsection{Behaviours and practices}

All respondents owned and used at least one HE EEE. Of those, approximately $75 \%$ hoarded home entertainment electronic products that they no longer wanted or used, $60 \%$ gifted, sold or disposed (GSD) of at least one HE electronic product since 2012, and $42 \%$ GSD of a HE electronic product since 2015.

Respondents owned more HE electronics than they used in every product category (Figure 1). Most respondents owned at least one TV (96\%), audio device (89\%), video player (62\%), and Nintendo game console (62\%). Of those, the most commonly owned products were Plasma TVs (81\%), portable speakers (65\%), Smart TVs (60\%), radios (54\%), DVD players (50\%) and the Nintendo Wii (42\%). Smart TVs had the highest use-to-ownership ratio. No respondents used their black and white TV. Overall, products that accompanied TV sets (e.g. video players, TiVo \& settop boxes, or audio devices) had higher ownership and use rates than most game consoles. The Nintendo Wii and DS had the highest game console ownership rates, yet they also had the smallest use rates. The Sony PlayStation 4 had the highest use-to-ownership ratio for game consoles. The HE categories with the lowest ownership rate were black and white TVs and virtual reality (VR) sets.

On average respondents owned 2.8 TV sets (1.6 Plasma TVs, 1 Smart TV), 1.4 video players, 1.1 TiVo and settop boxes, 2.6 audio entertainment devices (1.1 portable speakers) and 0.2 game consoles, with a total of 11.8 


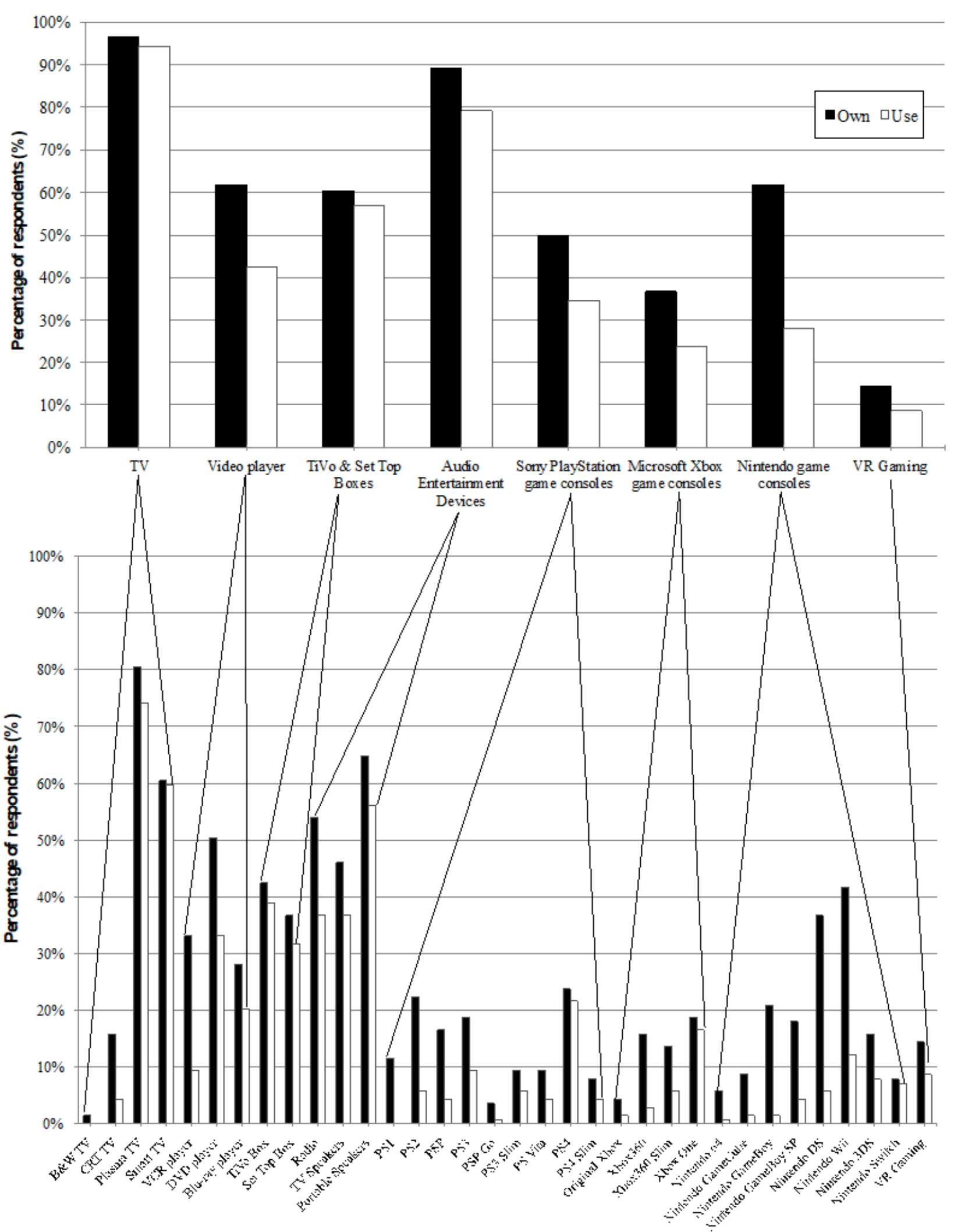

FIGURE 1: Proportion of respondents owning and using at least one home entertainment electronic product in Southampton in 2018 ( $n=139$ ).

HE devices owned per household. The products with the highest proportion of multiple devices were plasma TVs (43\%), portable speakers $(27 \%)$, radios $(20 \%)$ and smart TVs (19\%). The game console with the highest proportion of multiple devices was the Nintendo DS (10\%).

Almost all respondents (97\%) purchased their HE EEE through an electronics retailer as brand new products, and approximately a quarter of respondents were gifted $\mathrm{HE}$ 
products. Only a small minority of respondents opted to purchase second-hand EEE (i.e. from eBay, CeX shop, second-hand shop - Table 1).

Since $2012,81 \%$ of respondents had purchased new HE products in addition to what they already owned (not as replacements - Table 2), and $19 \%$ had only purchased new products to replace their old ones. The most common additionally purchased products were TVs (60\%) and specifically smart TVs (37\%), followed by Sony PlayStation game consoles (see Appendix 3 for a complete breakdown of additionally purchased products). Almost no respondents had purchased additional audio entertainment devices.

Most respondents (60\%) reported not planning any HE EEE purchases for 2018. The rest indicated plans of purchasing new TVs (mostly smart TVs), Sony PlayStations (mostly PlayStation 5), VR gaming sets and Set-Top Boxes (Table 3).

Approximately $60 \%$ of respondents had gifted, sold or disposed (GSD) of at least one HE electronic item since 2012 (5 years ago) and 42\% had GSD of items since 2015 (2 years ago). TVs were the most commonly GSD of devices in both instances, followed by audio entertainment devices and Nintendo game consoles (Figure 2).

Specifically, plasma TVs, radios, and Nintendo Wii consoles were the most frequently GSD of HE electronic products. The majority of respondents had gifted products to family and friends, taken them to Household Waste Recycling Centres (HWRCs), or thrown them out via general waste bin (Table 4). It was common for relatively newer models of EEE such as plasma TVs or PlayStation 3 consoles to be gifted to family or friends, whereas older products such black and white TVs, CRT TVs and VCR players to be taken to HWRCs.

The majority of respondents (39\%) reported gifting, selling or disposing of new/relatively new HE EEE because they wanted a more up-to-date model (Table 5). Respond-

TABLE 1: Respondents' purchasing options for home entertainment electronics in Southampton in 2018 ( $\mathrm{n=139).}$

\begin{tabular}{|c|c|c|}
\hline Purchasing Options & Number of respondents $(\mathrm{N})$ & Proportion of respondents (\%) \\
\hline Electronics retailer & 134 & 96.4 \\
\hline Second-hand shop & 5 & 3.6 \\
\hline CeX shop & 4 & 2.9 \\
\hline Gifted from family and friends & 35 & 25.2 \\
\hline Bought from family and friends & 13 & 9.4 \\
\hline eBay & 1 & 0.7 \\
\hline
\end{tabular}

TABLE 2: Home entertainment (HE) electronic products additionally purchased (not purchased as replacement products) by respondents since $2012(n=138)$.

\begin{tabular}{|c|c|c|}
\hline HE EEE Categories & Number of respondents $(\mathrm{N})$ & Proportion of respondents (\%) \\
\hline TV & 82 & 59.4 \\
\hline Video Player & 11 & 8.0 \\
\hline TiVo \& Set-Top Boxes & 25 & 18.1 \\
\hline Audio Entertainment Devices & 42 & 0.1 \\
\hline Sony PlayStation game consoles & 28 & 20.3 \\
\hline Microsoft Xbox game consoles & 15 & 10.9 \\
\hline Nintendo game consoles & 16 & 11.6 \\
\hline VR Gaming & 5 & 3.6 \\
\hline Other & 3 & 2.2 \\
\hline No additional items bought (only replacements) & 26 & 18.8 \\
\hline
\end{tabular}

TABLE 3: Respondents' planned purchases for home entertainment (HE) electronic products in 2018 ( $\mathrm{n}=139$ )products) by respondents since $2012(n=138)$.

\begin{tabular}{|c|c|c|}
\hline HE EEE Categories & Number of respondents $(\mathrm{N})$ & Proportion of respondents (\%) \\
\hline TV & 27 & 19.4 \\
\hline Video player & 0 & 0.0 \\
\hline TiVo \& Set-Top Boxes & 11 & 7.9 \\
\hline Audio Entertainment & 9 & 6 \\
\hline Game consoles \& VR & 26 & 18.7 \\
\hline Other & 5 & 3.6 \\
\hline Not planning on purchasing anything & 83 & 59.7 \\
\hline
\end{tabular}




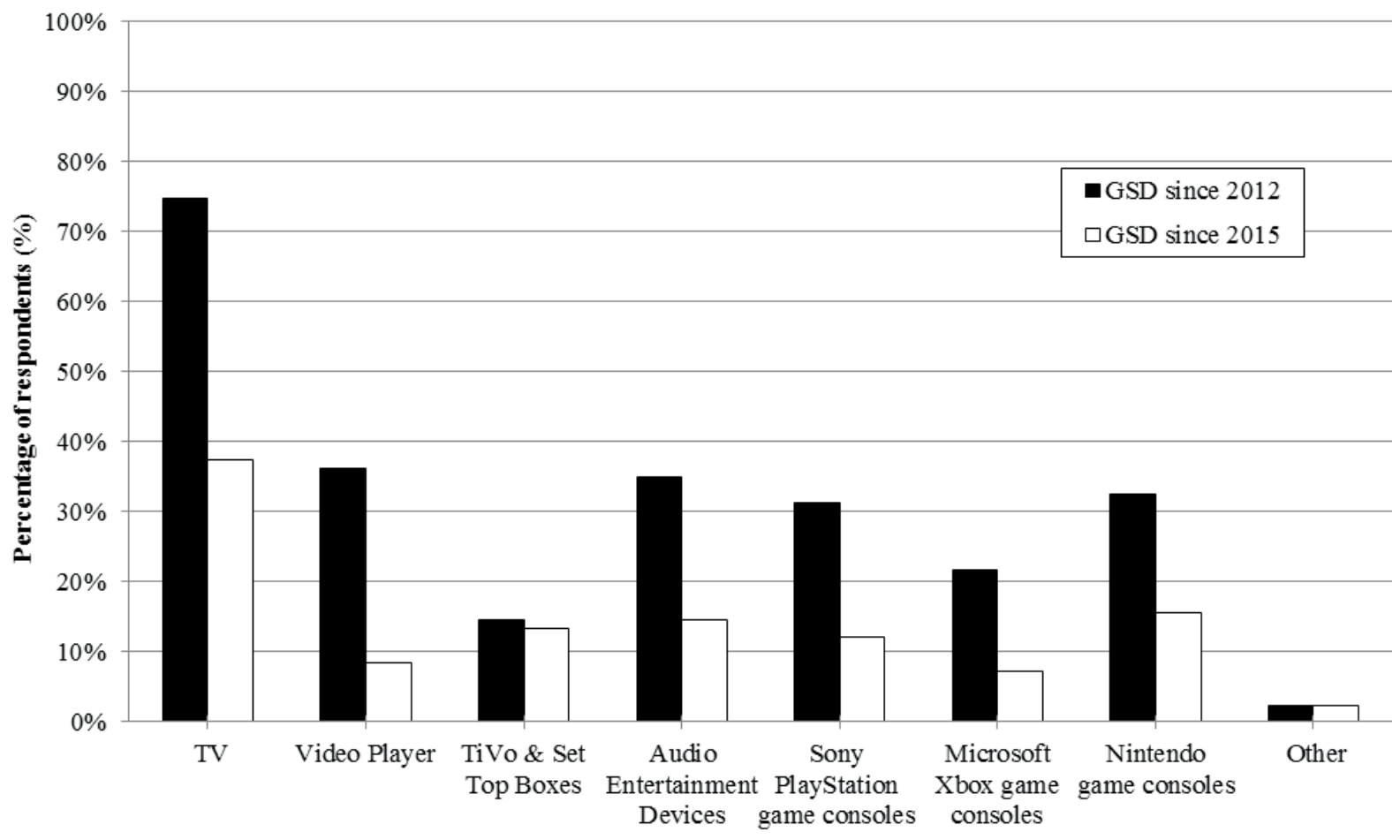

FIGURE 2: Proportion of respondents who gifted, sold or disposed (GSD) of home entertainment electronics of since 2012 and 2015.

ents also commonly disposed of HE products because they did not need them anymore.

\subsection{Hoarding practices}

Overall, $75 \%$ of respondents reported hoarding HE EEE, of which $55 \%$ and $32 \%$ (respectively) were also storing vide- otape and DVD products that they no longer used or wanted (Table 6). A high proportion of respondents hoarded game consoles and audio entertainment devices (Figure 3). The most commonly hoarded items were videotape products ( $42 \%$ of respondents hoarded at least one), Nintendo DS consoles (31\%), Nintendo Wii consoles (29\%), VCR Play-

TABLE 4: Gifting, selling and disposing routes for end-of-life (EoL) home entertainment (HE) electronics ( $n=83$ ).

\begin{tabular}{|c|c|c|}
\hline EoL routes of HE EEE & Number of respondents $(\mathrm{N})$ & Proportion of respondents (\%) \\
\hline Sold online & 6 & 7.2 \\
\hline Gave to family or friends & 57 & 68.7 \\
\hline Sold to CeX shop & 7 & 8.4 \\
\hline Threw out via general waste bin & 14 & 16.9 \\
\hline Sold to family or friends & 3 & 3.6 \\
\hline Gave to charities & 10 & 12.0 \\
\hline Dumped away from house & 1 & 1.2 \\
\hline Gave away via online free recycling & 0 & 0.0 \\
\hline Took to HWRC & 24 & 28.9 \\
\hline Left outside house & 8 & 9.6 \\
\hline Threw out via recycling bin & 12 & 14.5 \\
\hline
\end{tabular}

TABLE 5: Reasons for gifting, selling and disposing of end-of-life home entertainment electronics $(n=83)$.

\begin{tabular}{l|l} 
Reasons & Number of respondents (N) Proportion of respondents (\%) \\
\hline The item was dated and broken and needed replacing & 17 \\
\hline The item was working properly, but I wanted a more up-to-date model & \\
\hline The item was new/relatively new but had stopped working and needed replacing & 20.5 \\
\hline I was gifted a more up-to-date model & 23 \\
\hline I decided I did not need it nor did I need a replacement & 27.7 \\
\hline
\end{tabular}


TABLE 6: Respondent responses on the ownership and use of videotape and DVD products $(n=104)$.

\begin{tabular}{|c|c|c|c|c|}
\hline \multirow{2}{*}{ Responses } & \multicolumn{2}{|c|}{ Videotape products } & \multicolumn{2}{|c|}{ DVD products } \\
\hline & No. of respondents $(\mathrm{N})$ & Proportion of respondents (\%) & No. of respondents $(\mathrm{N})$ & Proportion of respondents (\%) \\
\hline Yes, and I still use them & 15 & 13.9 & 64 & 59.3 \\
\hline Yes, and I no longer want them & 59 & 54.6 & 34 & 31.5 \\
\hline No, I have given them all away & 34 & 31.5 & 10 & 9.3 \\
\hline Total & 108 & 100.0 & 108 & 100.0 \\
\hline
\end{tabular}

ers (24\%), Nintendo GameBoy consoles (19\%), DVD players (17\%), PlayStation 2 consoles (17\%) and radios (17\%) (Figure 2). On average respondents hoarded 1.5 Nintendo consoles, 0.8 Sony PlayStation consoles and audio devices, and 0.6 TVs and video players, with a total of $4.8 \mathrm{HE}$ devices hoarded per household. The products with the highest proportion of multiple hoarded devices were Nintendo DS consoles (9\%), portable speakers (7\%) and radios (7\%).

The functional value ('I may need it someday') placed on $\mathrm{HE}$ EEE is the most important factor influencing respondent hoarding habits (Figure 4). Both sentimental ('I'm too attached to the item') and social ('One day I'll find someone to give it to, who will really want it') reasons for hoarding ranked as second most important influencing factors. Approximately $45 \%$ of respondents agreed that lack-of-awareness (LoA) of what else to do with the item was an important influencing factor for hoarding of $\mathrm{HE}$ electronics. Monetary reasons for hoarding ('I paid too much money just to get rid of it') were ranked the least important hoarding factor.

\subsection{Dispositions, tendencies and opinions}

The functional value ('I may need it someday') placed on HE EEE was the most important influencing factor for respondent hoarding tendencies (Figure 5). For hoarding tendencies, social reasons to hoard ('One day l'Il find someone to give it to, who will really want it') were ranked higher than sentimental reasons ('I'm too attached to the item'). Lack-of-Awareness ('I don't know what else to do with it, so I keep it') was ranked third most important influencing factor alongside sentimental hoarding reasons. Monetary reasons were ranked as the least important influencing factor for respondent hoarding tendencies.

When gifted a new HE electronic product, the majority of respondents indicated that they would keep both the old and newly gifted products, signifying a tendency to hoard (Figure 6). More than half of respondents also reported that they would get rid of the old product once gifted a newer model. Hardly any respondents reported that they would keep the old product and dispose of the newly gifted model.

Similar to hoarding practices vs. tendencies, the gifting, selling and disposing tendencies of HE electronics were also examined to ensure responses from all participants $(n=139)$, including the ones who hadn't previously gifted, sold or disposed of products $(n=53)$. When examining respondent tendencies on the EoL management routes, the majority of respondents (86\%) reported that they would opt

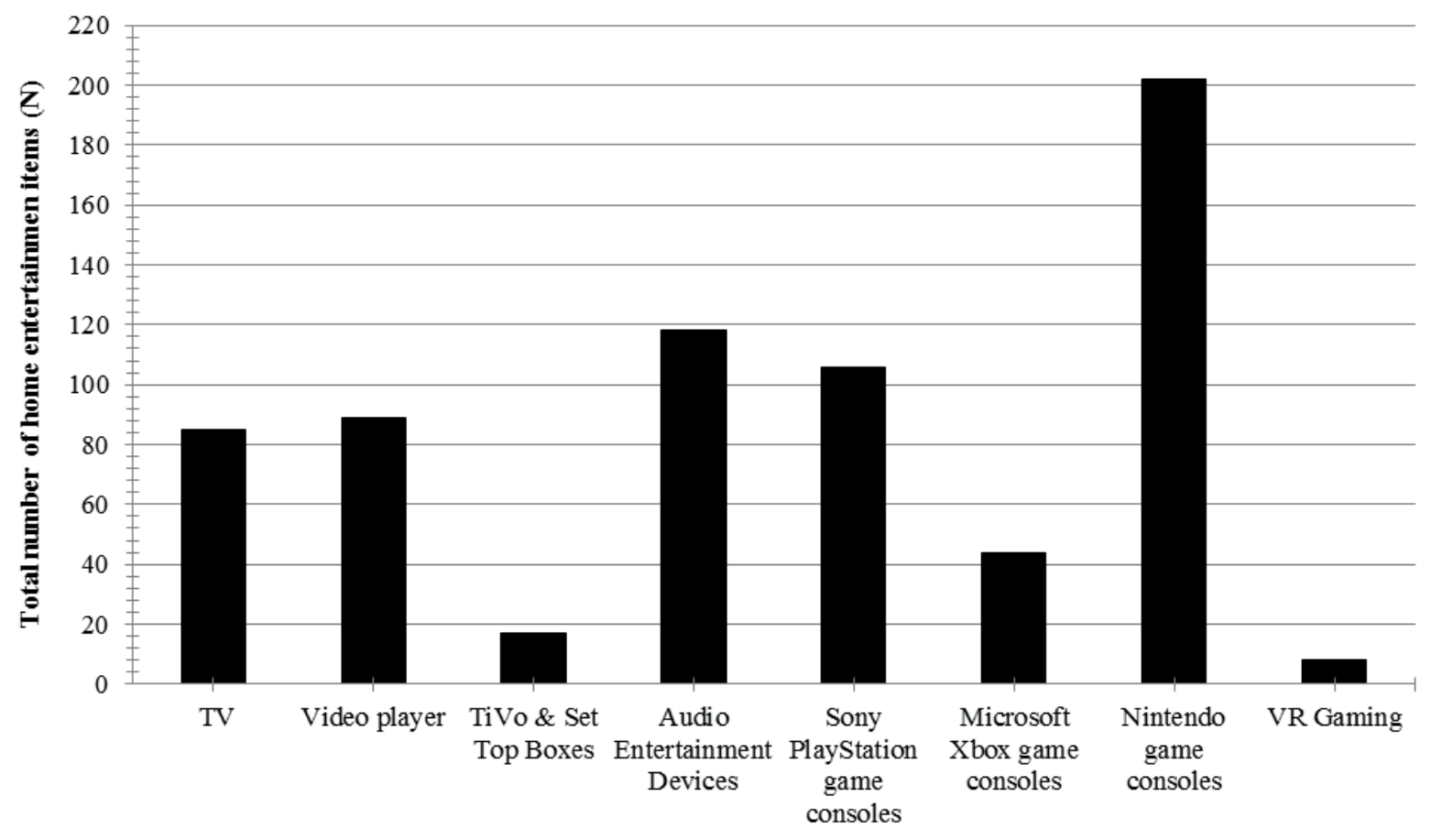

FIGURE 3: Total number of home entertainment items hoarded by respondents $(n=104)$. 


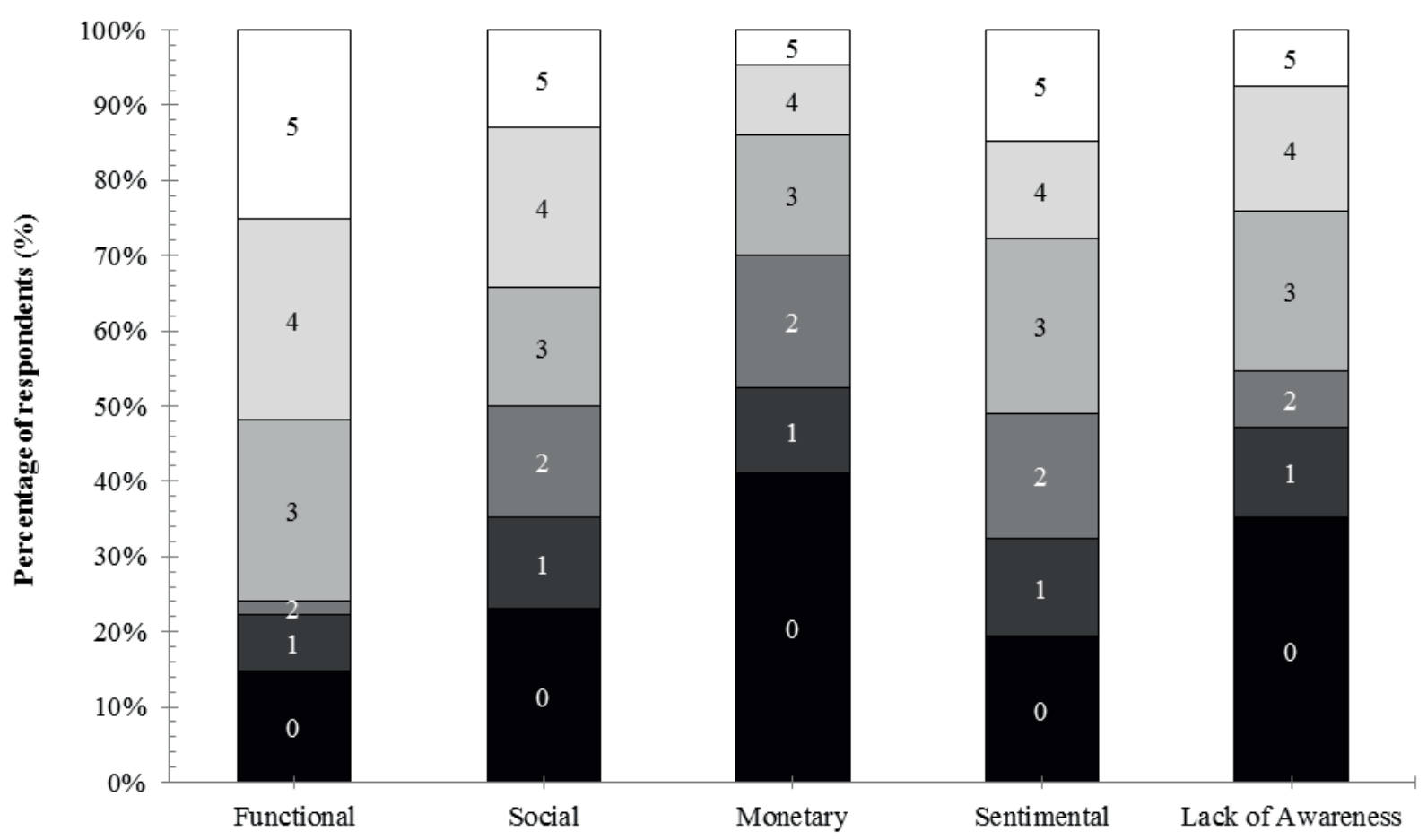

FIGURE 4: Reasons influencing respondent hoarding practices (Proportion of respondents who disagree: 0 , to completely agree: 5 , $n=104)$.

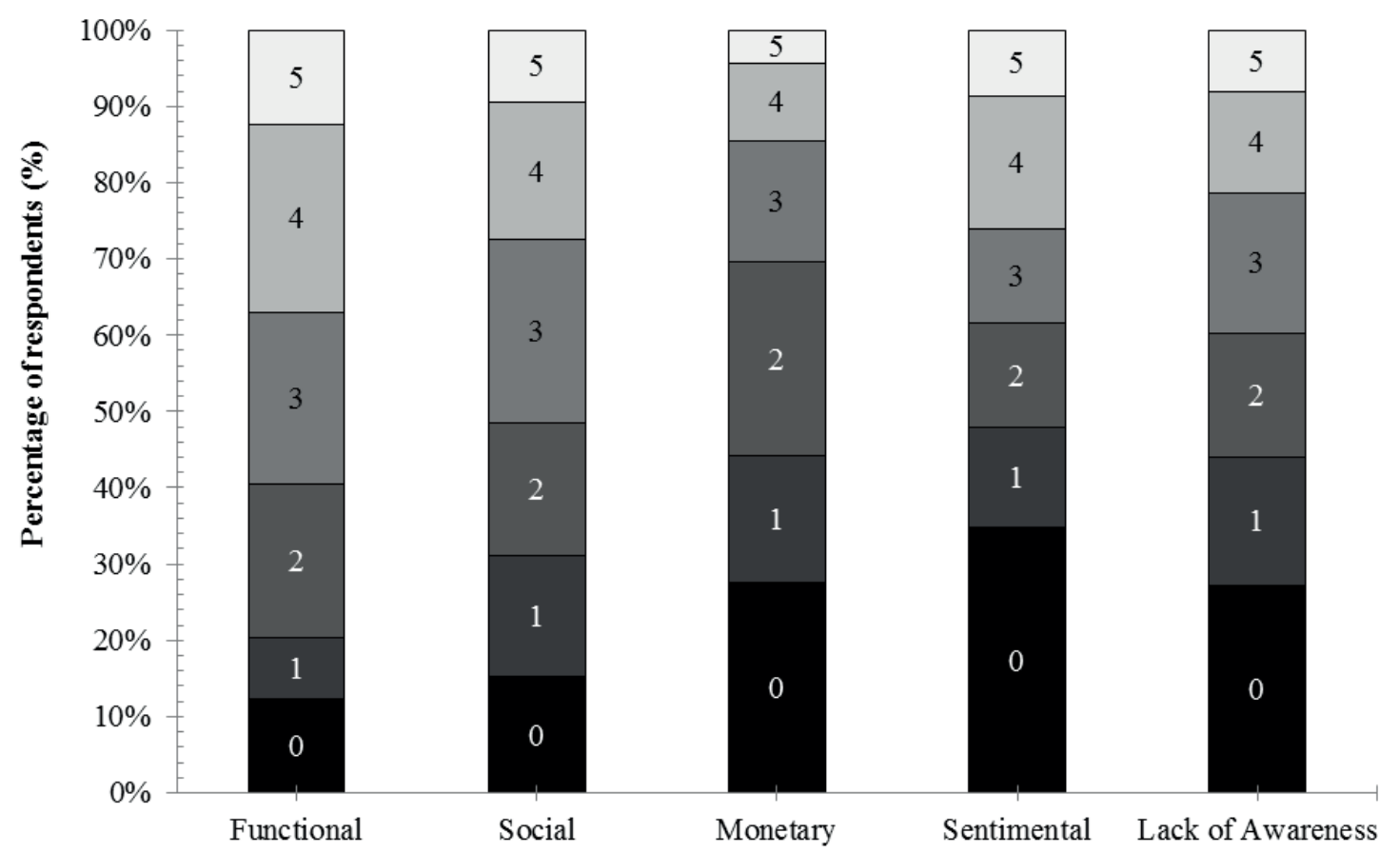

FIGURE 5: Reasons influencing respondent hoarding tendencies (Proportion of respondents who disagree: 0 , to completely agree: 5 , $\mathrm{n}=139$ ).

to 'give away' their products, first to family and friends, and then to charities (Figure 7). Respondents would sell their unwanted EEE as their second most common EoL management option, with $49 \%$ opting to sell items online, $30 \%$ to friends and family and $23 \%$ to a reuse shop (e.g. CeX).

The third most common route for respondents' EoL management tendencies was recycling of WEEE, with approximately $38 \%$ opting to take them to a HWRC, $25 \%$ using online recycling and $20 \%$ throwing them out via recycling bin (Figure 7). Fewer respondents reported tendencies of throwing WEEE out via general waste bin, or leaving them outside/ away from their house.

When it came to purchasing HE electronics, $74 \%$ of respondents agreed that they would wait for their EEE to stop working before purchasing a newer model; $61 \%$ agreed that they would wait for their EEE to become dated before mak- 


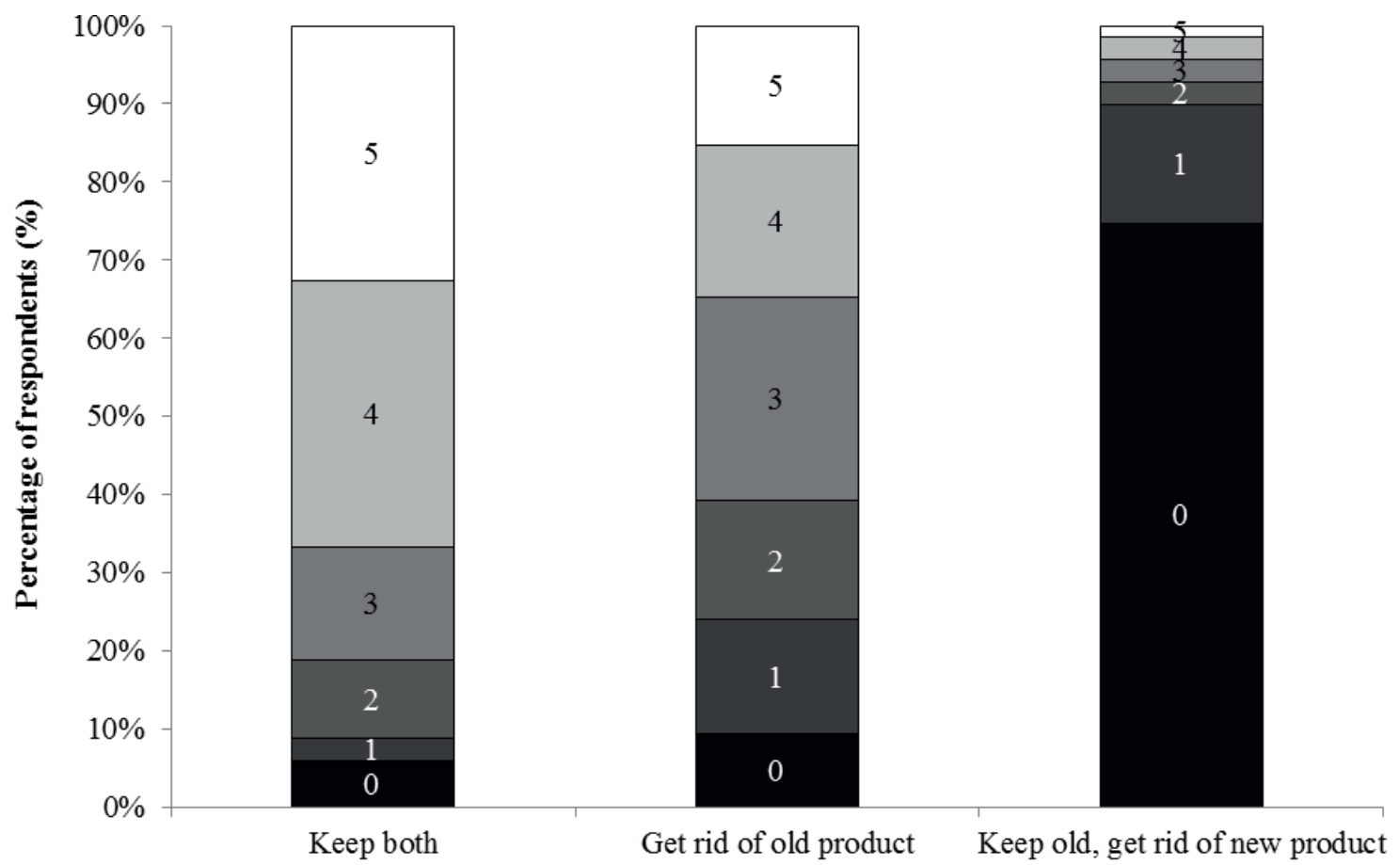

FIGURE 6: Respondent tendencies for the end-of-life management of their old home entertainment electronic products when gifted a newer model (Proportion of respondents who disagree: 0 , to completely agree: $5, n=139$ ).

ing a new purchase; and $37 \%$ agreed that they like to purchase the newest model of HE equipment that is currently on the market. Around $16 \%$ of respondents agreed that if they kept their HE EEE for long enough, their monetary value would increase. The majority of respondents (89\%) would not dispose of their TV and only use their phone or tablet, even though $30 \%$ of them claimed to watch television via their phone or tablet more often than via their TV.

Based on replacement cycles, the most lifecycle of HE products was 4-5 years (Figure 8). No respondents believed that TVs and game consoles should be replaced every year, and just a small proportion (2.2\%) would replace their products only once they stop working.

\subsection{Demographic characteristics and hoarding}

A statistically significant association was found between respondent age groups and hoarding (whether someone hoarded or no - Table 7) at the 0.05 level with a p-value of 0.019 . Statistically fewer respondents than expected from the age group of 25-44 years hoarded, and statistically more respondents than expected from the age group of 45-65 years hoarded HE WEEE. No association was found between all other demographic variables (gender, deprivation level, educational level, household size and storage space) and hoarding habits.

A statistically significant difference was determined between hoarding reasons (i.e. functional, social, sentimental, monetary and lack of awareness) at the 0.05 level (DF=4, p-value $<0.0005$ ). It was determined that significantly more respondents considered functional reasons ("I may need it someday") as important influencing factors for hoarding when compared to all other hoarding reasons (Table 8). Fewer respondents rated monetary reasons as important influencing factors for the hoarding of HE EEE, habits when compared to functional, social and sentimental reasons.

A statistically significant difference was found between respondent's age group and two of the five hoarding reasons, namely monetary and lack-of-awareness (LoA) reasons (Table 9). Significantly more respondents from the youngest age group (18-24 years) considered LoA as an important influencing factor for hoarding, compared to all other age groups (Table 10). Similarly, significantly more respondents from the younger age groups (18-24 and 2544 years) agreed that monetary reasons influenced their hoarding of HE (W)EEE when compared to the $65+$ age group. No significant difference was found between all other demographic variables and hoarding reasons.

\subsection{End-of-life routes}

A significant difference was found between the EoL management routes of gifting, selling and disposing at the 0.05 level ( $D F=10, p<0.0005)$. Significantly more respondents would opt for giving to family and friends as their primary EoL management route. Similarly, more respondents would choose for giving to charities, selling online and taking HE (W)EEE to the HWRC as their second, third and fourth EoL management routes. Overall, no significant difference was found between all other routes (e.g. selling to CeX, throwing out via recycling bin, etc.).

\section{DISCUSSION}

\subsection{Evolution of HE electronics}

HE electronics have evolved from analogue to digital, to 'smart' and interactive technologies. The timelines (Appendix 1) show that although consumer-based audio and 


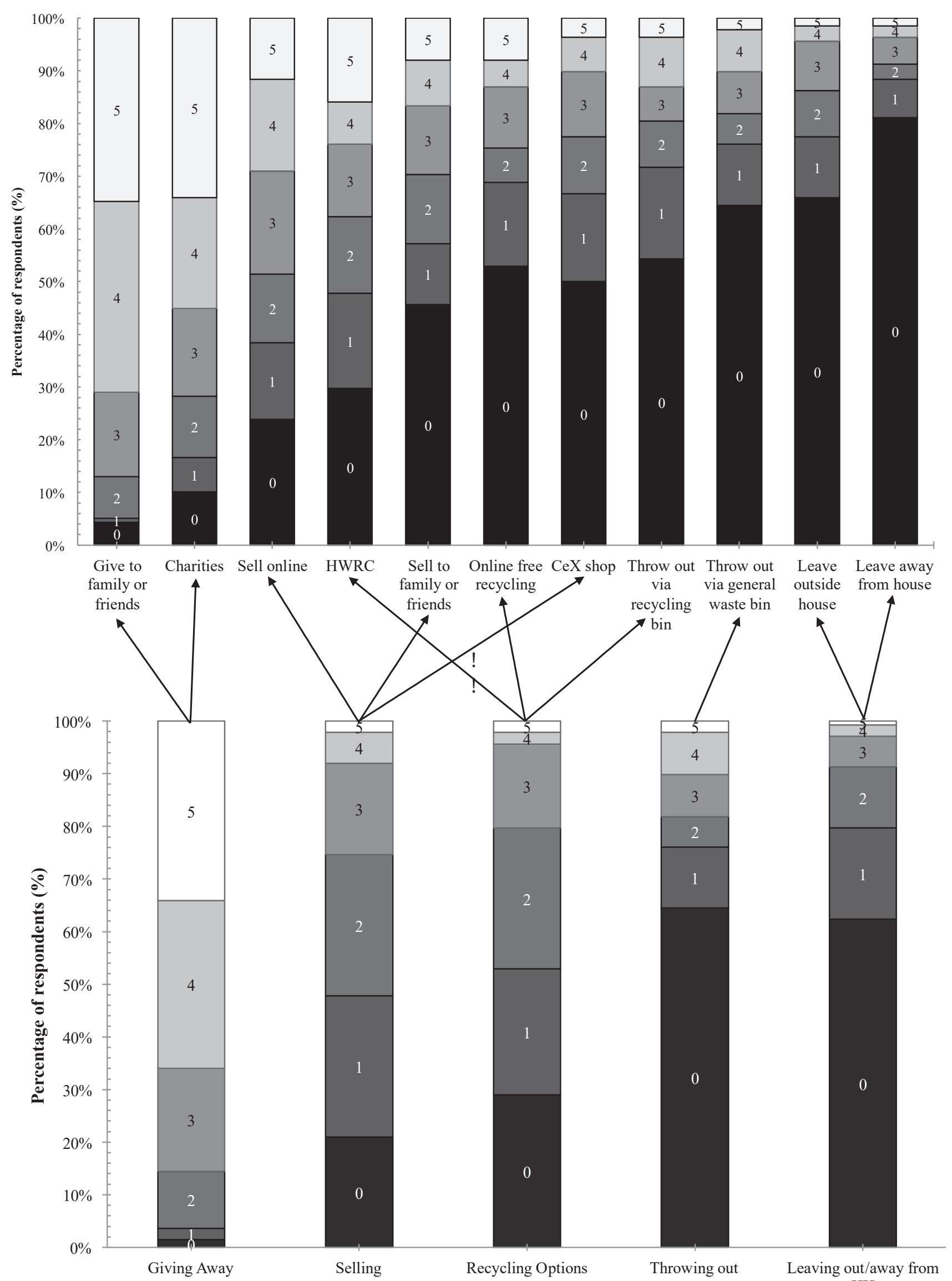

FIGURE 7: Respondent thoughts on the GSD routes of end-of-life management of home entertainment EEE (Proportion of respondents who disagree: 0 , to completely agree: $5, n=139$ ). 


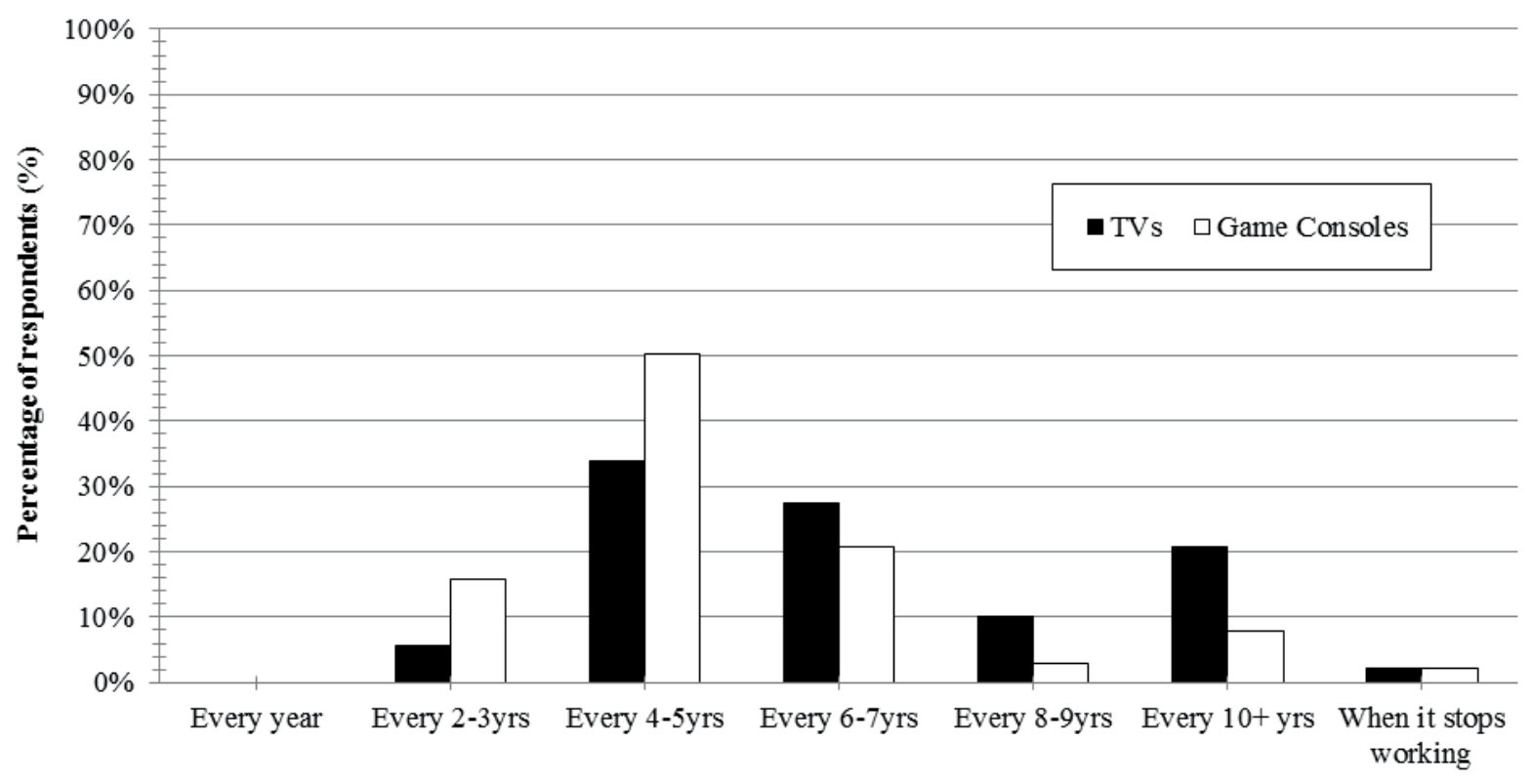

FIGURE 8: Appropriate replacement time for home entertainment electronics (years) ( $n=139)$.

television technologies were emerging in the early 1900s, their production flourished after WWII when HE products became a staple in consumer households. Technological advancements were accompanied by growing consumer demand and competition between manufacturers for market dominance. It wasn't until the 1980s when the industry properly manifested itself into a consumer-oriented economy, following the onset of the first compact disc players, video recorders and games consoles, which sold countless of units worldwide (Kang \& Schoenung, 2005). At that time, many companies that previously dominated the market like RCA or Atari were replaced by emerging companies such as Sony, Nintendo and Samsung. These new companies

TABLE 7: Chi-square results for association between age groups and hoarding habits for home entertainment WEEE $(n=139)$.

\begin{tabular}{|c|c|c|c|}
\hline & Hoarded & Not hoarded & Total \\
\hline \multirow[t]{3}{*}{$18-24$ years } & 38 & 9 & 47 \\
\hline & 35.2 & 11.8 & \\
\hline & 1.2 & -1.2 & \\
\hline \multirow[t]{3}{*}{ 25-44 years } & 22 & 16 & 38 \\
\hline & 28.4 & 9.6 & \\
\hline & -2.8 & 2.8 & \\
\hline \multirow[t]{3}{*}{$45-64$ years } & 33 & 5 & 38 \\
\hline & 28.4 & 9.6 & \\
\hline & 2.0 & -2.0 & \\
\hline \multirow[t]{3}{*}{$65+$ years } & 11 & 5 & 16 \\
\hline & 12 & 4 & \\
\hline & -0.6 & 0.6 & \\
\hline Total & 35 & 104 & 139 \\
\hline
\end{tabular}

Chi-square $=9.914, D F=3, p$-value $=0.019$

For all age groups, top row figures are observed counts, middle row are expected counts, and bottom row are residual Z-scores. For Z-scores a value of $>1.96$ indicates statistical significance. transformed HE EEE into an essential part of consumers' lives. Since the 1980s, features and capabilities of EEE have evolved using cheaper materials, while manufactured under higher technological standards and complexity (Kang \& Schoenung, 2005). Shorter product lifespans and quicker adoptions of new technologies have triggered subsequent upsurges in electronic waste (McCollough, 2009; Ongondo \& Williams, 2011a). Similar to the replacement of analogue technologies by digital devices during the digital switchover of 2012, it can be predicted that the increase in purchases of affordable 'smart' technologies that begun in 2015 will result in the replacement of digital devices like plasma/LCD TVs or DVD players in the near future (Ongondo et al., 2011b).

In current 'throwaway societies' consumers often replace EEE because they are no longer attracted to/satisfied by them (fashion obsolescence), or because a technologically superior product is introduced on the market (technological obsolescence) (McCollough, 2009). The concept of obsolescence is reflected in this study's results since the majority of respondents discarded HE EEE that were working properly because they wanted a more up-to-date model (Table 5). The concept of planned product obsolescence driven by manufacturers who knowingly produce 'disposable goods' to promote repetitive consumption is often discussed in current literature (Williams, 2016; McCollough, 2009; Ongondo \& Williams, 2011a). However, findings from this study show that less than $3 \%$ of respondents discarded items that were new but had stopped working (Table 5), indicating that fashion and technological obsolescence were more prevalent across the surveyed sample instead. On average, respondents replaced game consoles more frequently than TVs, suggesting that planned obsolescence is more common amongst smaller HE devices (i.e. game consoles) rather than larger products such as TVs.

To achieve sustainable consumption under a $\mathrm{CE}$ and enhance resource efficiency, product lifespans must be 
TABLE 8: Chi-square results for association between age groups and hoarding habits for home entertainment WEEE ( $n=139)$.

\begin{tabular}{|c|c|c|c|c|}
\hline & Social & Sentimental & Monetary & $\begin{array}{c}\text { Lack of } \\
\text { Awareness }\end{array}$ \\
\hline \multirow[t]{5}{*}{ Functional } & 52 & 56 & 72 & 67 \\
\hline & 24 & 23 & 13 & 23 \\
\hline & 32 & 29 & 22 & 18 \\
\hline & -3.771 & -3.334 & -6.165 & -4.310 \\
\hline & 0.000 & 0.001 & 0.000 & 0.000 \\
\hline \multirow{5}{*}{\multicolumn{2}{|c|}{ Social }} & 45 & 48 & 50 \\
\hline & & 40 & 20 & 32 \\
\hline & & 23 & 39 & 26 \\
\hline & & -0.104 & -4.169 & -1.797 \\
\hline & & 0.917 & 0.000 & 0.072 \\
\hline \multirow{5}{*}{\multicolumn{3}{|c|}{ Sentimental }} & 56 & 47 \\
\hline & & & 21 & 31 \\
\hline & & & 30 & 30 \\
\hline & & & -3.912 & -1.819 \\
\hline & & & 0.000 & 0.069 \\
\hline \multirow{5}{*}{\multicolumn{4}{|c|}{ Monetary }} & 27 \\
\hline & & & & 46 \\
\hline & & & & 34 \\
\hline & & & & -1.859 \\
\hline & & & & 0.063 \\
\hline
\end{tabular}

Series of Wilcoxon tests assessing significant differences between all hoarding reasons at the 0.005 level.

For each hoarding reason, the top-row figures are negative ranks (times that value of column < row). The second-row figures are positive ranks (times that value of column > row). The third-row figures are the rank ties (times that value of column $=$ row). The fourth-row figures are the Z-scores (based on positive ranks) for each Wilcoxon test. The bottom row figures are the $p$-values for each Wilcoxon test; figures of 0.000 indicate a $p$ value $<0.0005$.

extended through the use of more durable materials, while the standardisation of product size, shape and location of components will aid dismantling, prolong use and reuse, and ensure material recovery (Long et al., 2016). Current manufacturing techniques are driven by consumer demands and changes in fashion, making modern electronics challenging to disassemble and recover. To encourage the repair and reconditioning of HE EEE rather than their replacement, the cost of repair should be made cheaper than the purchase of new products (McCollough, 2009). Consumer perceptions on the stigma around the 'poorer quality' of reused, repaired or recycled products compared to new electronics should also be broken (Lin \& Huang, 2012; Long et al., 2016).

TABLE 9: Results of Kruskal-Wallis test for statistical significance between age groups and hoarding reasons $(n=139)$

\begin{tabular}{c|c|c|c|c} 
Functional & Social & Sentimental & Monetary & Lack of Awareness \\
\hline 3.537 & 0.667 & 4.348 & 9.284 & 18.524 \\
\hdashline 0.316 & 0.881 & 0.226 & 0.026 & 0.000 \\
\hline
\end{tabular}

$\mathrm{DF}=3, \mathrm{a}=0.05$

Top row figures show the Kruskal-Wallis $\mathrm{H}$, and the bottom row figures are the $\mathrm{p}$-values; figures of 0.000 indicate a $\mathrm{p}$ value $<0.0005$
TABLE 10: Results of Mann-Whitney $U$ tests comparing between age groups and the monetary and lack-of-awareness hoarding factors $(n=139)$

\begin{tabular}{|c|c|c|}
\hline & Monetary & Lack of Awareness \\
\hline \multirow[t]{3}{*}{$18-24$ and $25-44$ years } & 418.000 & 246.000 \\
\hline & -0.656 & -3.282 \\
\hline & 0.512 & 0.001 \\
\hline \multirow[t]{3}{*}{$18-24$ and $45-64$ years } & 544.500 & 359.000 \\
\hline & -1.012 & -3.320 \\
\hline & 0.312 & 0.002 \\
\hline \multirow[t]{3}{*}{$18-24$ and $65+$ years } & 97.500 & 85.000 \\
\hline & -2.719 & -3.026 \\
\hline & 0.007 & 0.002 \\
\hline \multirow[t]{3}{*}{$25-44$ and $45-64$ years } & 336.000 & 422.500 \\
\hline & -1.422 & 747.500 \\
\hline & 0.155 & 0.967 \\
\hline \multirow[t]{3}{*}{$25-44$ and $65+$ years } & 62.000 & 120.500 \\
\hline & -2.728 & -0.620 \\
\hline & 0.006 & 0.535 \\
\hline \multirow[t]{3}{*}{$45-64$ and $65+$ years } & 121.500 & 164.000 \\
\hline & -1.886 & -0.656 \\
\hline & 0.059 & 0.512 \\
\hline Total & 35 & 104 \\
\hline
\end{tabular}

For each age group pair, the top row figures show the Mann Whitney- $U \mathrm{H}$ value, the middle rows are the Z-scores, and the bottom rows are the p-values; figures of 0.000 indicate a $p$ value $<0.0005$

\subsection{Ownership and hoarding of HE electronics}

\subsubsection{Ownership levels}

Ownership levels for EEE in economically developed nations have increased considerably over the past few decades, transforming cities into hugely exploitable potential DUMs (Pierron et al., 2017). The availability of EEE from inuse and hibernating stocks will affect the exploitability of a mine (Ongondo et al., 2015; Pierron et al., 2017). Ownership levels for HE EEE in the surveyed zones of Southampton were high; with an average of 12 and a maximum of 45 devices found per household. These results are translated into estimates for the exploitation potential of DUMs at local and national levels in Table 11. Overall, we estimate that there are over 1 million HE devices owned and $\sim 440,000$ $\mathrm{HE}$ devices hoarded in Southampton; scaling up these data suggests that there are $>150$ million HE EEE owned and $\sim 61$ million HE devices hoarded in UK households. The estimations reported in Table 11 may not be entirely representative at a national level due to the survey's small sample size but they provide a realistic order of magnitude value that shows the potential country-wide opportunity for circular economy resource mining. The results are broadly representative of Southampton since the city was randomly sampled across four different deprivation zones.

Almost all survey respondents owned at least one TV, TV-related item (i.e. video player, TiVo, set-top box) and an audio entertainment device (Figure 1). On average, each surveyed household owned 2.8 TV sets, 2.6 audio enter- 
TABLE 11: Total number of home entertainment items owned and hoarded on average in Southampton and the United Kingdom (UK) (estimated from survey results).

\begin{tabular}{|c|c|c|c|c|}
\hline \multirow{2}{*}{ Home Entertainment EEE } & \multicolumn{2}{|c|}{ Southampton* } & \multicolumn{2}{|c|}{$\mathrm{UK}^{\star *}$} \\
\hline & Owned & Hoarded & Owned & Hoarded \\
\hline TVs & 254,620 & 55,780 & $35,450,360$ & $7,766,187$ \\
\hline Video players & 124,685 & 58,405 & $17,359,712$ & $8,131,655$ \\
\hline TiVo \& Set Top Boxes & 97,123 & 11,156 & $13,522,302$ & $1,553,237$ \\
\hline Audio Entertainment Devices & 240,839 & 77,436 & $33,531,655$ & $10,781,295$ \\
\hline Sony PlayStation game consoles & 121,404 & 69,561 & $16,902,878$ & $9,684,892$ \\
\hline Microsoft Xbox game consoles & 54,468 & 28,874 & $7,583,453$ & $4,020,144$ \\
\hline Nintendo game consoles & 173,247 & 132,560 & $24,120,863$ & $18,456,115$ \\
\hline VR Gaming & 13,781 & 5,250 & $1,918,705$ & 730,935 \\
\hline Total & $1,080,167$ & 439,023 & $150,389,928$ & $61,124,460$ \\
\hline
\end{tabular}

tainment devices, 1.4 video players, and 1.1 TiVo/set-top boxes. These findings broadly correspond with those reported by BARB (2018) and the Energy Saving Trust (2012), where $95.4 \%$ of households were considered 'digital/interactive TV homes' in 2018, with the average UK household owning 2.0-2.3 TV sets. Overall, ownership of game consoles was less common among respondents compared to TV-related equipment, although more common amongst the younger age groups. The most frequently owned game consoles were the Nintendo Wii, DS and PlayStation 4 (Figure 1). A UK-wide survey by Statista (2018) determined that $36 \%$ of consumers claimed to own at least one game console in 2017, of which the majority reported owning a Nintendo Wii and an Xbox360. The slight higher value of game console ownership from this study is probably due to the higher proportion of younger demographic that completed the survey. The study's findings indicated that the Nintendo Wii was the most frequently owned game console, which is in line with the Statista's survey results.

Determining ownership levels and use patterns is essential when evaluating the potential of DUMs. Knowledge gained can also assist in estimating the scale and types of soon-exploitable resources at both local and national levels. This way, waste-processing infrastructure can adapt their technological capacities to efficiently recover the soon-available EEE types (Ongondo et al., 2015). The findings of this study can be used to give a broadly representative idea of the extent of ownership of HE EEE across Southampton and UK households (e.g. over 12 million UK households own at least one TV, and almost 8 million own at least one Nintendo game console; See Table 12).

\subsubsection{Hoarding levels}

Stockpiled and hoarded HE electronics represent currently inaccessible, high-grade, hibernating stocks, especially rich in metals (Golev et al., 2016). Similar to ownership, hoarding levels of HE EEE provide information on the scope of urban stocks and help map out the complete exploitation potential of a DUM. Hoarding of HE electronics was clearly evident in the surveyed zones of Southampton, with $75 \%$ of respondents claiming to have hoarded at least one type of HE device. Tables 11 and 12 translate hoarding levels into an estimate of the 'hibernating' stocks available locally and nationally, assuming that the survey results are representative. We predict that an average of 450,000 HE electronic devices are hoarded in Southampton and that over 61 million are hoarded across the UK (Table 11). We estimate that 71,530 Southampton households and almost 10 million UK households hoard at least one HE item, with at least 5 million households hoarding at least one TV,

TABLE 12: Total number of households owning and hoarding at least one home entertainment item across surveyed zones, including estimations for Southampton and the UK.

\begin{tabular}{|c|c|c|c|c|c|c|}
\hline \multirow{2}{*}{ Home Entertainment EEE } & \multicolumn{2}{|c|}{ Surveyed Zones } & \multicolumn{2}{|c|}{ Southampton* } & \multicolumn{2}{|c|}{$U_{K}^{\star \star}$} \\
\hline & Owning & Hoarding & Owning & Hoarding & Owning & Hoarding \\
\hline TVs & 134 & 52 & 87,936 & 34,124 & $12,243,165$ & $4,751,079$ \\
\hline Video players & 86 & 53 & 56,437 & 34,781 & $7,857,554$ & $4,842,446$ \\
\hline TiVo \& set top boxes & 84 & 16 & 55,124 & 10,500 & $7,674,820$ & $1,461,871$ \\
\hline Audio entertainment devices & 124 & 58 & 81,374 & 38,062 & $11,329,496$ & $5,299,281$ \\
\hline Sony PlayStation consoles & 69 & 47 & 45,281 & 30,843 & $6,304,317$ & $4,294,245$ \\
\hline Microsoft Xbox consoles & 51 & 28 & 33,468 & 18,375 & $4,659,712$ & $2,558,273$ \\
\hline Nintendo game consoles & 86 & 71 & 56,437 & 46,593 & $7,857,554$ & $6,487,050$ \\
\hline Virtual reality gaming & 20 & 8 & 13,125 & 5,250 & $1,827,338$ & 730,935 \\
\hline Total & 139 & 109 & 91,217 & 71,530 & $12,700,000$ & $9,958,993$ \\
\hline
\end{tabular}

*HCC (2008) **ONS (2016) 
video player and game consoles (Table 12). The hoarding levels reported in Table 12 assume that each household only hoards one HE item from each product category, yet the survey results indicate that $20-36 \%$ of respondents actually hoarded more than one audio entertainment device, PlayStation and Nintendo game console, and $14 \%$ hoarded more than one TV. This suggests that the number of devices hoarded in reality across UK households could be closer to the estimates shown in Table 11.

The survey indicated that the most commonly hoarded electronics were videotapes (VHS, Betamax), DVDs, Nintendo game consoles (DS, Wii and GameBoy), VCR players, DVD players and radios (Figure 3 ). The results show that game consoles were owned less frequently than TV sets, yet hoarded more. The most commonly hoarded items were smaller HE equipment (i.e. videotapes, DVDs, Nintendo DS etc.). This corresponds to other research that also determined the higher likelihood of storing small EEE (Darby \& Obara, 2005; Ongondo et al., 2011b). The hoarding of non-digital devices (i.e. videotape products; VCR players) could potentially be explained by the lower level of consumer awareness on the effect of the digital switchover on VCR players, which led to their stockpile once the switchover was complete (Ongondo et al., 2011b). The electronic items hoarded the least (i.e. smart TVs, Nintendo Switch, Xbox One and PlayStation 4 game consoles) were relatively new models of HE electronics (less than five years old) that may yet be hoarded in the future.

Understanding the reasons behind consumer hoarding of HE EEE is very important when considering their EoL management, to tailor collection and take-back facilities in a way that addresses and alleviates hoarding barriers. In this study most respondents illustrated a significant tendency to hoard, mainly due to the attributed residual functional value they placed on HE EEE ("I may need it someday"), followed by their perceived social value ("One day l'll find someone to give it to, who will really want it") (Figure 5). This is reflected in other studies, where respondents stockpiled old (W)EEE mainly as 'back-ups' or with the aim of giving them to someone else (Ongondo et al., 2015; MFE, 2006; Ongondo \& Williams, 2011a). Sentimental reasons to hoard were ranked more highly when respondents recalled past behaviours than when they reported on their hoarding dispositions, suggesting that consumers become attached to electronic products more often than they think they do. A significantly higher proportion of the younger age groups (18-24 years) considered lack-of-awareness (LoA) and product cost as important reasons to hoard their unwanted EEE (Table 10). Other studies reflected similar results, where the price of EEE and LoA were important influencing factors for stockpiling and EoL decisions of younger consumers (see Ongondo \& Williams, 2011a; MFE, 2006; Ylä-Mella et al., 2015; Li et al., 2012; Pierron et al., 2017).

\subsection{Current end-of-life EEE management practices}

In the case of purchasing HE electronics, the majority of respondents would wait for a product to become dated/ stop working before they purchased a newer model. More than a third of respondents were influenced by fashion and technological obsolescence, as they liked to purchase the newest models on the market. Almost all respondents purchased their new products from electronic retailers, rather than second-hand shops, reinforcing the concept discussed by Long et al. (2016) on the perceived inferior quality of reused, repaired or recycled products. Recent purchasing habits commonly involved acquiring new smart TVs, portable speakers or PlayStation 4 consoles. These findings are in line with 2017 sales figures, where $82 \%, 74 \%$ and $76 \%$ of the market-share was attributed to smart TVs, PlayStation 4 consoles and portable speakers, respectively (J'son \& Partners, 2017; D’Angelo, 2017; Business Wire, 2017).

The study indicated that when HE products were in working condition but of no use to their owners, they were most frequently given to relatives and friends or donated to charities. This decision can be attributed to the residual functional value assigned to HE products, which can be beneficial in prolonging the products' lifetime and encouraging reuse. Respondents also reported a disposition to sell their unwanted EEE online, or take them to HWRCs. The disposition to recycle EEE was evident among respondents, yet their disposal habits reflected a higher probability of discarding items via general refuse. Ongondo \& Williams (2011a) determined that consumers tend to send bulkier items to HWRCs, while medium-sized items with residual value (such as HE electronics) are donated to charities or given to friends and family, which match this study's findings. Broken equipment or smaller items such as remote controls or game console handsets usually do not warrant a trip to the HWRC and are most often hoarded or disposed of in the general waste (Ongondo \& Williams, 2011a; Pierron et al., 2017). It was also evident that respondents' perceived residual value of $(W) E E E$ would cease once products became very dated or were broken.

The average replacement time for HE electronics was 4-5 years, with game consoles being replaced slightly sooner than TVs. Unless hoarded, this makes the majority of HE EEE purchased since 2012 soon-exploitable resources within a DUM. HE equipment lifecycles are also illustrated through respondents' purchasing and disposal habits. The majority of respondents had purchased additional HE products in the last 5 years, as well as disposed of old electronics, demonstrating a clear average 5-year lifecycle. These findings match the current literature, which suggests that most EEE are discarded within 3 to 6 years (Hursthouse et al., 2017; Ongondo et al., 2015; Cooper, 2002).

\subsection{Distinct Urban Mine potential}

The high ownership levels for HE electronics in Southampton make it an extremely plausible metal-specific DUM, abundant in ferrous metals, aluminium, copper and plastics (Haig et al., 2012). Its potential as a DUM is strongly influenced by the public's decision to hoard or dispose of their (W)EEE. Reuse and recycling are positive decisions for accessing the DUM whereas discarding and hoarding prevent the recovery of resources. It is essential to incorporate information on the EoL decisions of consumers into waste management efforts. Access to an urban mine is closely related to the prevention of stockpiling and thus the willingness of consumers to give up their products (Ongon- 
do et al., 2015; Li et al., 2012). Promoting the collection and recycling of $(W) E E E$ through awareness campaigns could help consumers associate EoL electronics with material recovery, and deter from their perceived residual value. Awareness campaigns can also be applied to improve public knowledge on the disposal methods for HE (W)EEE, by providing information on collection centres and schemes. To encourage recycling behaviour, recovery schemes must incorporate more accessible and convenient collection points, with proximity to commonly visited urban hubs (e.g. transport hubs or shopping precincts) (Ylä-Mella et al., 2015; Morris \& Metternicht, 2016). Additionally, collection services could incorporate monetary incentives (e.g. cash payments or vouchers), to encourage participation of younger age groups who frequently hoard electronics due to monetary reasons (Ongondo \& Williams, 2011b; Li et al., 2012). Such incentives could also promote the faster release of (W)EEE from consumers' homes, ensuring access to recoverable materials in a shorter timeframe. A study by Hursthouse et al. (2017) on the efficient recovery of critical raw material under a closed-loop economy, determined that working closely with local social enterprises and schools to collect (W)EEE might encourage higher recovery rates, due to their local dimension and trusted relationship with the public. Under the same concept, Ongondo et al. (2015) suggested that universities could be utilised as recovery centres for (W)EEE. Targeting the recovery of larger items (e.g. plasma TVs) or devices with a higher proportion of multiple hoarded devices (e.g. game consoles) might be an easier way to influence consumer hoarding due storage space constraints. This approach could gradually stimulate consumers to view the EoL of all (W)EEE differently (Hursthouse et al., 2017).

\section{CONCLUSIONS}

This study has assessed the effect of consumer behaviour on the release of $\mathrm{HE}(\mathrm{W}) \mathrm{EEE}$ into the circular economy. It provides original contributions to the current literature by establishing, presenting and analysing previously unavailable data on the ownership, use and hoarding levels of HE EEE in a typical city DUM, and the reasons behind their hoarding. In a city with a population of $\sim 240,000$ in the UK, ownership levels were very high, with an average of 12 home entertainment items owned per household. This makes urban areas extremely plausible as DUMs; we estimate that there are over 1 million HE devices owned and $\sim 440,000 \mathrm{HE}$ devices hoarded in Southampton and $>150$ million HE EEE owned and 61 million HE devices hoarded in UK households. Hoarding is therefore common, especially for smaller or older equipment, due to their perceived residual value. HE product lifecycles averaged 4-5 years. The most common EoL routes were donating to relatives, friends or charities; hoarding; recycling via Household Waste Recycling Centres; or discarding items in general refuse. To encourage the recovery of EoL $\mathrm{HE}$ equipment in a DUM, convenient and accessible collection points should be promoted via awareness campaigns and incentives.

The most common respondent behaviours involved hoarding of small (W)EEE, the recycling of larger products via HWRCs, and the gifting/donating of working EEE with perceived residual value. EoL HE equipment was often hoarded as a back-up (i.e. stockpiling) or with the aim of giving them away in the future. More respondents from younger age groups considered lack-of-awareness of disposal options and the steep price of purchased items as important influencing factors for hoarding. The study also quantified soon-exploitable and hibernating stocks within a large urban area's surveyed zones, to predict product and material yields that could be made available to a DUM in the near future. To ensure recovery of used EEE and WEEE, waste management efforts should:

- Promote the recycling and reuse through awareness campaigns on collection schemes for consumer electronics.

- Establish convenient and accessible used EEE and WEEE collection points to encourage regular (periodic) harvesting and incentives.to encourage reuse / recycling behaviour, with potential monetary incentives.

- Target the recovery of items that take up more space in consumer households (larger equipment or with a higher proportion of multiple devices).

- Encourage faster reuse of EEE via donations to charities, relatives or friends in order to gradually stimulate consumers to view EoL WEEE differently.

\section{REFERENCES}

Baldé, C.P., Wang, F., Kuehr, R., Huisman, J. (2015). The global e-waste monitor - 2014, United Nations University. IAS - SCYCLE. Bonn, Germany.

Benton, R. (2014). Reduce, Reuse, Recycle ... and Refuse. Journal of Macromarketing, 35(1), 111-122.

Berglund, C., and Matti, S. (2006). Citizen and consumer: the dual role of individuals in environmental policy. Environmental Politics, 15(4), 550-571.

Broadcasters Audience Research Board (BARB). (2018). Television ownership in private domestic households 1956-2018 (millions). [online] Available at: http://www.barb.co.uk/resources/tv-ownership/ [Accessed 13 Mar. 2018].

Business Wire. (2017). Top 3 Trends Impacting the Global Portable Speaker Market Through 2021. [online] Available at: https:// www.businesswire.com/news/home/20170215005057/en/ Top-3-Trends-Impacting-Global-Portable-Speaker [Accessed 3 Apr. 2018].

Cherry, C. E. and Pidgeon, N. F. (2018). Is sharing the solution? Exploring public acceptability of the sharing economy. Journal of Cleaner Production, 195, 939-948.

Cooper, T. (2002). Durable consumption: reflections on product life cycles and the throwaway society. Life-Cycle Approaches to Sustainable Consumption Workshop Proceedings, International Institute for Applied Systems Analysis, Luxemburg, December 2002, 15-27.

D’Angelo, W. (2017). PS4 vs Xbox One vs Wii U Global Lifetime Sales January 2017 Update. [online] VGChartz. Available at: http://www. vgchartz.com/article/267593/ps4-vs-xbox-one-vs-wii-u-globallifetime-salesjanuary-2017-update/ [Accessed 5 Apr. 2018].

Darby, L. and Obara, L. (2005). Household recycling behaviour and attitudes towards the disposal of small electrical and electronic equipment. Resources, Conservation and Recycling, 44(1), 17-35.

Energy Saving Trust (2018). Powering the Nation. Household electricity habits revealed. [online] London: Energy Saving Trust. Available at: http://www.energysavingtrust.org.uk/sites/default/files/reports/ PoweringthenationreportC0332.pdf [Accessed 15 Mar. 2018].

Fletcher, C.A. \& Dunk, R.M. (2018). In the search for effective waste policy: Alignment of UK waste strategy with the circular economy. Detritus, 04, 48-62. 
Golev, A., Schmeda-Lopez, D., Smart, S., Corder, G. and McFarland, E. $(2016)$. Where next on e-waste in Australia? Waste Management, 58, 348-358

Haig, S., Morrish, L., Morton, R. and Wilkinson, S. (2012). Electrical product material composition. Overview of updated data within the Market Flows Model of Electronic Products. [online] WRAP. Available at: http://www.wrap.org.uk/sites/files/wrap

Hampshire County Council (HCC). (2008). Census Household Composition. [online] Available at: http://www3.hants.gov.uk/factsandfigures/population-statistics/census_pages/census_information/ pop_household_composition.htm [Accessed 15 Apr. 2018].

Hursthouse, A., Kelly, S., McPherson, W., Menzies, B., Mirzaeian, M. and Wood, D. (2017). WEEE collection and CRM recovery trials: piloting a holistic approach for Scotland. Conference on Environmental Science and Technology. Rhodes, Greece.

Imran, M., Haydar, S., Kim, J., Awan, M. and Bhatti, A. (2017). E-waste flows, resource recovery and improvement of legal framework in Pakistan. Resources, Conservation and Recycling, 125, 131-138.

Izatt, R., Izatt, S., Bruening, R., Izatt, N. and Moyer, B. (2014). Challenges to achievement of metal sustainability in our high-tech society. Chem. Soc. Rev., 43(8), 2451-2475.

J'son \& Partners (2017). Smart TV Market, 2010 - 2017. Market Watch. [online] J'son \& Partners Management Consultancy. Available at: http://json.tv/en/ict_telecom_analytics_view/smart-tv-market-2010-2017 [Accessed 14 Mar. 2018].

Kang, H. and Schoenung, J. (2005). Electronic waste recycling: A review of U.S. infrastructure and technology options. Resources, Conservation and Recycling, 45(4), 368-400.

Li, B., Yang, J., Song, X. and Lu, B. (2012). Survey on Disposal Behaviour and Awareness of Mobile Phones in Chinese University Students. Procedia Environmental Sciences, 16, 469-476.

Lin, P. and Huang, Y. (2012). The influence factors on choice behavior regarding green products based on the theory of consumption values. Journal of Cleaner Production, 22(1), 11-18.

Lodhia, S., Martin, N. and Rice, J. (2017). Extended Producer Responsibility for waste televisions and computers: A regulatory evaluation of the Australian experience. Journal of Cleaner Production, 164, 927-938.

Long, E., Kokke, S., Lundie, D., Shaw, N., ljomah, W. and Kao, C. (2016) Technical solutions to improve global sustainable management of waste electrical and electronic equipment (WEEE) in the EU and China. Journal of Remanufacturing, 6(1).

Martin, C. J. (2016). The sharing economy: A pathway to sustainability or a nightmarish form of neoliberal capitalism? Ecological Economics, 121, 149-159.

Massari, S. and Ruberti, M. (2013). Rare earth elements as critical raw materials: Focus on international markets and future strategies. Resources Policy, 38(1), 36-43.

McCollough, J. (2009). Factors impacting the demand for repair services of household products: the disappearing repair trades and the throwaway society. International Journal of Consumer Studies, 33(6), 619-626

Ministry for the Environment (MFE). (2006). Electrical and electronic equipment survey January 2006: A quantitative report. [online] Ministry for the Environment. Available at: http://www.mfe.govt. $\mathrm{nz} /$ publications/waste/electrical-and-electronic-equipment-survey-january-2006-quantitative-report/2 [Accessed 15 Mar. 2018].

Morris, A. and Metternicht, G. (2016). Assessing effectiveness of WEEE management policy in Australia. Journal of Environmental Management, 181, 218-230.

Office for National Statistics (ONS). (2016). Families and households in the UK - Office for National Statistics. [online] Available at: https:// www.ons.gov.uk/peoplepopulationandcommunity/birthsdeathsandmarriages/families/bulletins/familiesandhouseholds/2016 [Accessed 15 Apr. 2018]
Ongondo, F. and Williams, I. (2011a). Are WEEE in Control? Rethinking Strategies for Managing Waste Electrical and Electronic Equipment. In: S. Kumar, ed., Integrated Waste Management - Volume II. [online] InTech. DOI: 10.5772/20506. Available at: https://www. intechopen.com/books/integrated-waste-management-volume-ii/ are-weee-in-control-rethinking-strategies-for-managing-waste-electrical-and-electronic-equipment [Accessed 15 Mar. 2018].

Ongondo, F. and Williams, I. (2011b). Greening academia: Use and disposal of mobile phones among university students. Waste Management, 31(7), 1617-1634.

Ongondo, F. and Williams, I. (2012). A critical review of the UK household WEEE collection network. Proceedings of the Institution of Civil Engineers - Waste and Resource Management, 165(1), 13-23.

Ongondo, F., Williams, I. and Cherrett, T. (2011a). How are WEEE doing? A global review of the management of electrical and electronic wastes. Waste Management, 31(4), 714-730.

Ongondo, F., Williams, I. and Keynes, S. (2011b). Estimating the impact of the "digital switchover" on disposal of WEEE at household waste recycling centres in England. Waste Management, 31(4), 743-753.

Ongondo, F., Williams, I. and Whitlock, G. (2015). Distinct Urban Mines: Exploiting secondary resources in unique anthropogenic spaces. Waste Management, 45, 4-9.

OpenDataCommunities.org. (2015). English Indices of Deprivation: map explorer 2015 (Index of Multiple Deprivation). [online] Available at: http://dclgapps.communities.gov.uk/imd/idmap.html [Accessed 12 Oct. 2017].

Osibanjo, O. and Nnorom, I. (2007). The challenge of electronic waste (e-waste) management in developing countries. Waste Management \& Research, 25(6), 489-501.

Osterley, R. and Williams, I.D. (2019). The social, environmental and economic benefits of reuse by charity shops. Detritus, 07, 29-35.

Pierron, X., Williams, I., Shaw, P. and Cleaver, V. (2017). Using choice architecture to exploit a university Distinct Urban Mine. Waste Management, 68, 547-556.

Saphores, J., Nixon, H., Ogunseitan, O. and Shapiro, A. (2009). How much e-waste is there in US basements and attics? Results from a national survey. Journal of Environmental Management, 90(11), 3322-3331.

Schluep, M., Hageluken, C., Kuehr, R., Magalini, F., Maurer, C., Meskers, C., Mueller, E., Wang, F. (2009). Recycling - From E-waste to Resources. United Nations Environment Programme and United Nations University, Germany.

Simon, F-G. \& Holm, O. (2018). Resources from recycling and urban mining: limits and prospects. Detritus, 02, 24-28.

Statista. (2018). Game consoles: ownership in Great Britain 2010-2017 Survey. [online] Available at: https://www.statista.com/statistics/288729/penetration-of-game-consoles-in-great-britain/ [Accessed 15 Apr. 2018].

Timlett. R. E. and Williams. I. D. (2009). The impact of transient populations on recycling behaviour in a densely populated urban environment. Resources Conservation \& Recycling, 53(9), 498-506.

van Barneveld, J., van der Veen, G., Enenkel, K., Mooren, C., Talman-Gross, L., Eckartz, K., Ostertag, K., Duque-Ciceri, N., Fischer, T., Gama, M., Scheidt, L., Wilts, H., Schäfer, L. and Fischer, S. (2016). Regulatory barriers for the Circular Economy: Lessons from ten case studies. [online] Amsterdam: Technopolis Group. Available at: https://www.technopolis-group.com/wp-content/ uploads/2017/03/2288-160713-Regulary-barriers-for-the-circular-economy_accepted_HIres.pdf [Accessed 13 Jan. 2018].

Williams, I. (2016). Global Metal Reuse, and Formal and Informal Recycling from Electronic and Other High-Tech Wastes. In: Metal Sustainability: Global Challenges, Consequences, and Prospects. 1st ed. John Wiley \& Sons, 23-51.

Williams, I.D. and Shaw, P.J. (2017). Editorial: Reuse: Fashion or future? Waste Management, 60, 1-2.

Ylä-Mella, J., Keiski, R. and Pongrácz, E. (2015). Electronic waste recovery in Finland: Consumers' perceptions towards recycling and re-use of mobile phones. Waste Management, 45, 374-384. 